\title{
Static and fatigue characterization of the Ti5553 titanium alloy
}

\author{
M. B. BETTAIEB ${ }^{1, *}$, A. LENAIN² and A. M. HABRAKEN",3

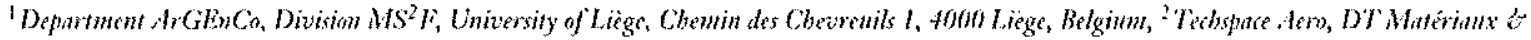

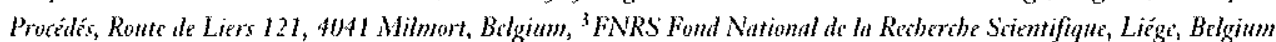

Rrcived in final form $2771 \mathrm{ly} 2012$

ABSTRACT This paper presents and discusses static (elastoviscoplastic and damage) and high-cycle fatigue characterization of two microstructures of the Ti5553 alloy. The difference between these wo microstructures is related to their heat treatment and precisely to the temperature of the final aging. For each microstructure, several tests were carried out to identify their static and fatigue properties and the test results were correlated to the microstructure, $A$ fractographic analysis of the rupture sections was performed in order to investigate the fracture medhanisms of the two microstructures. Finally, the fatigue properties of the two microstructures were compared with those found in results reported in the literature for two other classical titanium alloys used for aeronautical applications.

Keywords fractographic analysis; Goodman diagrams; high-cycle fatigne; static characterization; 'Ti5553 alloy.

NOMENCLATURE

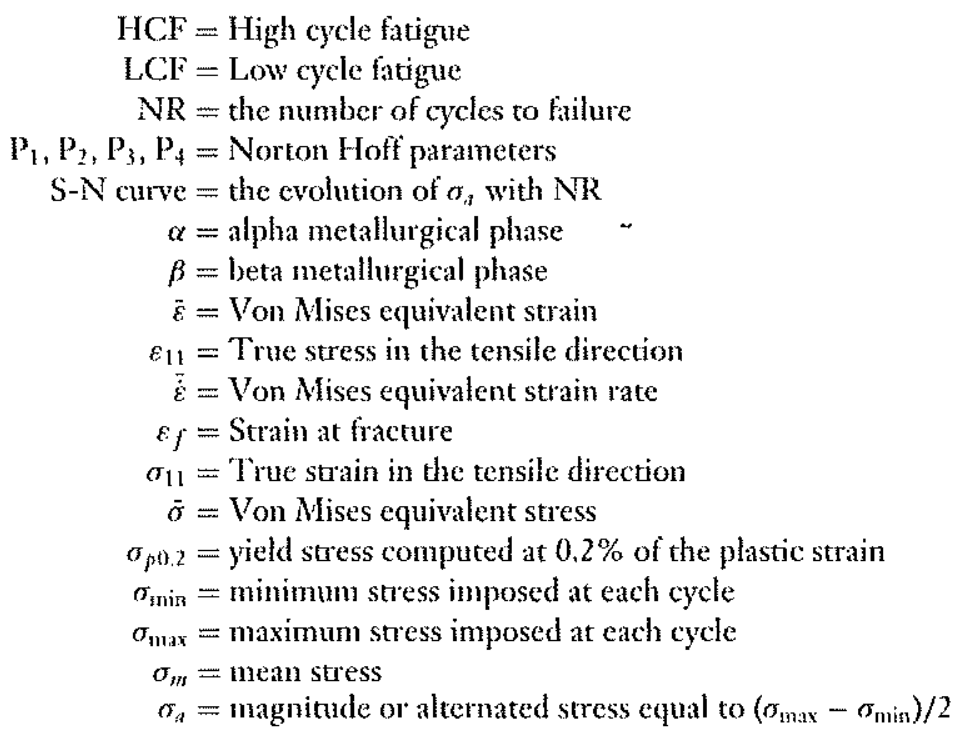

\section{INTRODUCTION}

Titanium alloys receive considerable interest due to their wide range of applications in the aerospace, automotive, chemical and medical industries. ${ }^{1-6}$ These alloys are selected for their low density, their good corrosion behaviour and their excellent mechanical properties. The well-known Ti-6Al-4V has been the most commonly used

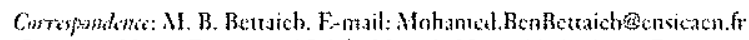

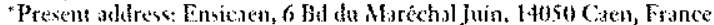

titanium alloy for aerospace components (e.g. fan disks, spools) for almost 50 years. However, the need to increase the strength of Ti- $6 \mathrm{Al}-4 \mathrm{~V}$ components combined with the alloy's inherent limitation due to its hardenability has created interest in other titanium alloys. Over the past few years, several scientific and industrial teams have identified Ti5553 as a promising alloy. ${ }^{7-10}$ Curently, little information is available regarding this relatively new alloy. Ti5553 is a high strength, near beta titanium al loy designed with excellent mechanical properties. It is a 
variation of the Russian alloy VI22" and is an altemative to the Ti-10-2-3 alloy. It provides a way of obtaining a microstructure of much greater strength than Ti-6Al-4V, leading to a lighter weight product.

Unfortunately, there is not a lot of information in the literanure about the mechanical behaviour (static and iatigue properties) of the Ti5553 alloy, and present work gives some experimental results and explanations about its mechanical behaviour. The microstructure of the studied alloy is correlated with the mechanical properties. The current paper investigates whether the high strength and the good ductility of this alloy are associated with high fatigue properties. The first motivation behind the study is the fact that the majority of aerospace and automotive components are submitted to cyclic loading: high-cycle fatigne (HCF) and low cycle fatigue (LCF) loadings. The second motivation is related to the insufficiency of data in the literature regarding reliable structure design under fatigue loads, ${ }^{10}$ Earlier studies have revealed a number of important factors underlying the fatigue behaviour of titanium alloys. It is reported in the literature ${ }^{1 ?-213}$ that the volume fraction and the morphology of the phases ( $\alpha$, $\beta$ ) in titanium alloys appear to be critical parameters for their mechanical properties in general and for their fatigue properties in particular. Indeed, the service life and reliability of these alloys depend on the microstructure obtained after hot working and final heat treatment and on the condition of the surface layer. $1,13,19,20$

In the present study, static (elastoviscoplasticity and damage) and high-cycle fatigue behaviour were investigated for two microstructures of the Ti5553 alloy, called hereafter Ti5553-1 and Ti5553-3. The first aging temperature of the heat treatment cycle was identical for the two microstructures. However the temperaturc of the second aging was different for each of the two microstructures: it was equal to $610^{\circ} \mathrm{C}$ for the Ti5553-1 microstructure and $670{ }^{\circ} \mathrm{C}$ for the Ti5553-3 microstructure. This final aging was responsible for the nucleation of the secondary $\alpha$ phase. The temperante of this aging determined the volume fraction and the morphology of these $\alpha$ precipitates. These microstructures are correlated with the static and the fatigue properties.

A tractographic analysis was performed on fatigue spec imens to understand the fracture mechanisms of the differcnt microstructures. Finally, the fatigue behaviour of the Ti5553 alloy was also compared with the fatigue behaviour of two other classical titanium alloys (Ti40 and Ti-6Al-4V) used in the aeronautic industry.

The outline of the paper is as follows:

- Section 'Materials' describes the studied material ('Ti5553 alloy), i.e. its chemical composition, heat treatment and microstructures;
- Section 'Elastoviscoplastic properties of the Ti5553 microstructures' presents the clastoviscoplastic properties of the two microstructures;

- Section 'Damage properties of the Ti5553 microstructures' details the damage properties of the 'Ti5553-1 and Tis 553-3 microstructures;

- Section 'Tatigue experiments and results' shows the fatigue experiments and results;

- Section 'Comparison of hatigue results of the two studied Ti5553 alloy microstructures with those of no other titinium alloys, Ti40 and 'Ti-6Al-4V' describes a comparison of the fatigue test results for both microstractures with that of other titanium alloys as described in results in the literature;

- Section 'Conclusions' presents sone overall conclusions.

\section{MATERIALS}

\section{General description of the studied microstructures}

The Ti5553 (Ti-5Al-5V-5Mo-3Cr) alloy is a metastable $\beta$ alloy. In fact, a large quantity of beta stabilizer elements such as $\mathrm{Mo}, \mathrm{V}, \mathrm{Fe}, \mathrm{Cr}$, etc, are present (see the chemical composition in Table 1). This alloy exhibits excellent hardenability and strength properties, making it attractive as a structural titanum alloy. Its transus temperature is about $860^{\circ} \mathrm{C}$. The Ti5553 alloy presents high sensitivity to the variation of the heat treatment and the thermomechanical treatment. This sensitivity has a significant impact on the microstructure as demonstrated in section 'Forging and heat treatment'.

\section{As received material}

The material used for the current study was a titunium alloy received from the Techspace Aero company (a menber of the Safran group) in the form of forged pancakes (Fig. 1). The forging of these pancakes was performed at $815^{\circ} \mathrm{C}$ on a 2500 ton forging press. The final thickness of these pancakes was equal to $47 \mathrm{~mm}$.

Table 1 Chenical composition of the Ti5553 alloy (values are in $w \%)$

\begin{tabular}{llllllll}
\hline & Mo & $\mathrm{Zr}$ & $\mathrm{Fe}$ & $\mathrm{V}$ & $\mathrm{Si}$ & $\mathrm{Al}$ & $\mathrm{C}$ \\
\hline Bottom & 4.82 & $<0.005$ & 0.3 & 4.93 & $<0.03$ & 5.26 & 0.009 \\
Top & 4.87 & $<0.005$ & 0.3 & 4.94 & $<0.03$ & 5.33 & 0.007 \\
& $\mathrm{O}$ & $\mathrm{N}$ & $\mathrm{Cr}$ & $\mathrm{Y}$ & $\mathrm{H}$ & & \\
\hline & & & $\mathrm{H}$ & & & \\
\hline Bottom & 0.14 & 0.005 & 3.04 & $<0.001$ & 0.006 & & \\
Tup & 0.14 & 0.004 & 3.05 & $<0.001$ & 0.004 & & \\
\hline
\end{tabular}




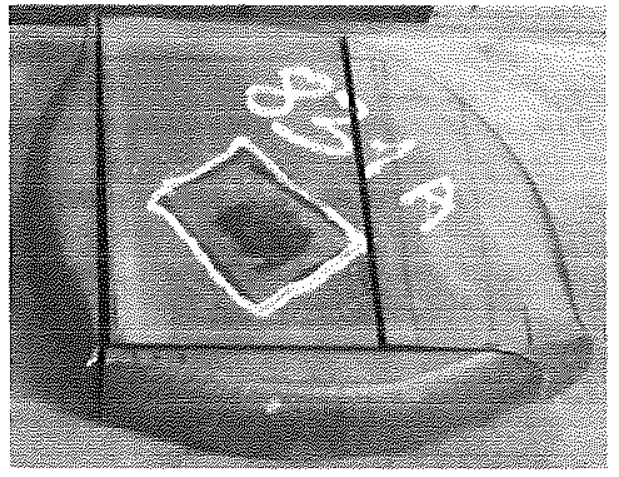

Fig. 1 forged pancake.

\section{Chemical composition of the billet}

The measured chemical composition from the top and the bottom of the pancake is reported in Table 1 .

The molybdenum equivalent (Mo equivalent) in terms of chemical composition is defined as follows: ${ }^{21}$

$$
\begin{aligned}
\text { wt } \% \text { Mo eq. }= & 1.0(w t \% \mathrm{Mo})+0.66(w t \% \mathrm{~V}) \\
& +0.33(w t \% \mathrm{~N})+3(w t \% \mathrm{Fe}) \\
& +3(w t \% \mathrm{Cr}) .
\end{aligned}
$$

Using the above table and formulae, the Mo equivalent of the present alloy was estimated (with the minimal composition) as 18.18 .

\section{Forging and heat treatment}

The final heat treatment used to generate each Ti5553 microstructures studied is shown in Fig. 2.

A detailed description of the heat treatnent cycle is given below:

- Ti5553-1: heat from room temperature up to $830^{\circ} \mathrm{C}+$ hold at $830^{\circ} \mathrm{C}$ for $2 \mathrm{~h}+$ air cooling + aging at $610^{\circ} \mathrm{C}$ for $8 \mathrm{~h}+$ air cooling.

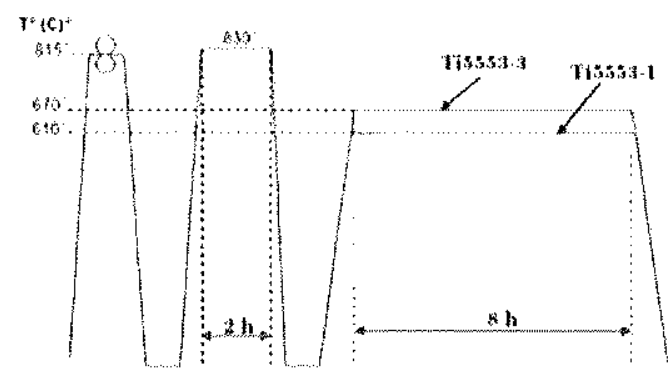

Fig. 2 forging of pancakes and final heat treastment cycle applied to generate the two nicrostructures of Ti5553 alloy.
- Ti5553-3: heat from room temperature up to 830 C $\mathrm{C}$ hold at $830^{\circ} \mathrm{C}$ for $2 \mathrm{~h}+$ air cooling + aging at $670^{\circ} \mathrm{C}$ for $8 \mathrm{~h}+$ air cooling.

\section{Microstructures of the Ti5553 alloy}

Figure 3 shows that the two generated microstructures are bi-modal, the primary $\alpha$ has a nodular morphology and the secondary $\alpha$ is lamellar. The first aging at $830^{\circ} \mathrm{C}$ (Fig. 2) was responsible for the nucleation of the nodules of $\alpha$. This aging was the same for both microstructures (Fig. 2), explaining why there is no difference between the morphology and the size of the nodular $\alpha$ phase of the two microstuctures. The only difference between the two microstructures is related to the temperature of the final aging. This temperature was responsible for the formation of the secondary $\alpha$ phase, which contains particles shaped like needles or very small plates. For the microstructure Ti5553-1, as shown in Fig. 3 (a), this flat structure is slightly thinner (compared to the secondary $\alpha$ phase of the Ti5553-3 microstmeture), due to a lower aging temperature $\left(610^{\circ} \mathrm{C}\right)$. In the Ti5553 alloy, the $\alpha$ phase is the main hardening mechanism. The size of the $\alpha$ particles has a significant effect on the static strength (section 'Elastoviscoplastic propertics of the 'Ti5553 microstuctures'), ductility (section 'Damage properties of the Ti5553 microstructures') and fatigue strength (section 'Fatigue experiments and results') of the studied microstructures.

\section{ELASTOVISCOPLASTIC PROPERTIES OF THE TIS553 MICROSTRUCTURES}

The mechanical behaviour of the two studied microstructures was previously determined in Refs $[2,3]$. Both studies clearly demonstrate that the materials exhibit an elastoviscoplastic behaviour.

In order to investigate the elastoviscoplastic behaviour of the two microstructures at room temperature, four strain rates were investigated through different tests: $5 \times 10^{-5}$ $\mathrm{s}^{-1}, 2 \times 10^{-4} \mathrm{~s}^{-1}, 4 \times 10^{-3} \mathrm{~s}^{-1}$ and $10^{-2} \mathrm{~s}^{-1}$. To check experiment repeatability, three duplicate tests were performed for each strain rate and cach microstructure.

\section{Elastic behaviour}

From several mechanical tests (uniaxial tensile tests at different strain rates and in different loading directions, plane strain tests, shear tests), it was previously demonstrated in Ref. [2] that the elastic behaviour of the two microstructures is isotropic and independent of the strain rate. Young's modulus was found in the present study to be equal to $112 \mathrm{GPa}$ and $108 \mathrm{GPa}$ for the Ti5553-1 and Ti5553-3 microstructures, respectively. These were 

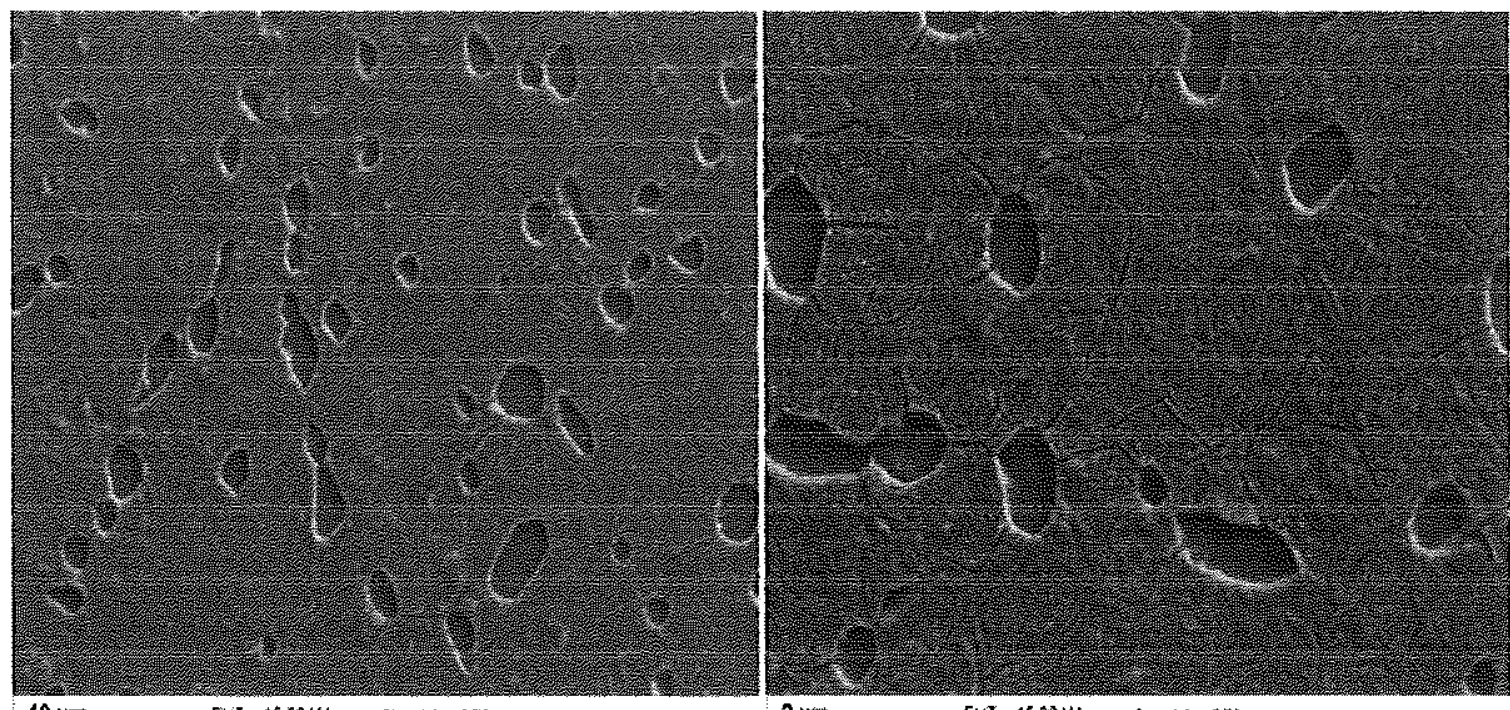

$10 \mathrm{mn}$

EHI $=1500 k$

Signd A $=S E 2$

$9 \mathrm{Ag} 2011$

$2 \mathrm{~mm}$

EHT: $=1500 \mathrm{~W}$

$\operatorname{sgn} A=32$

9 A $3 x+1$

(a)

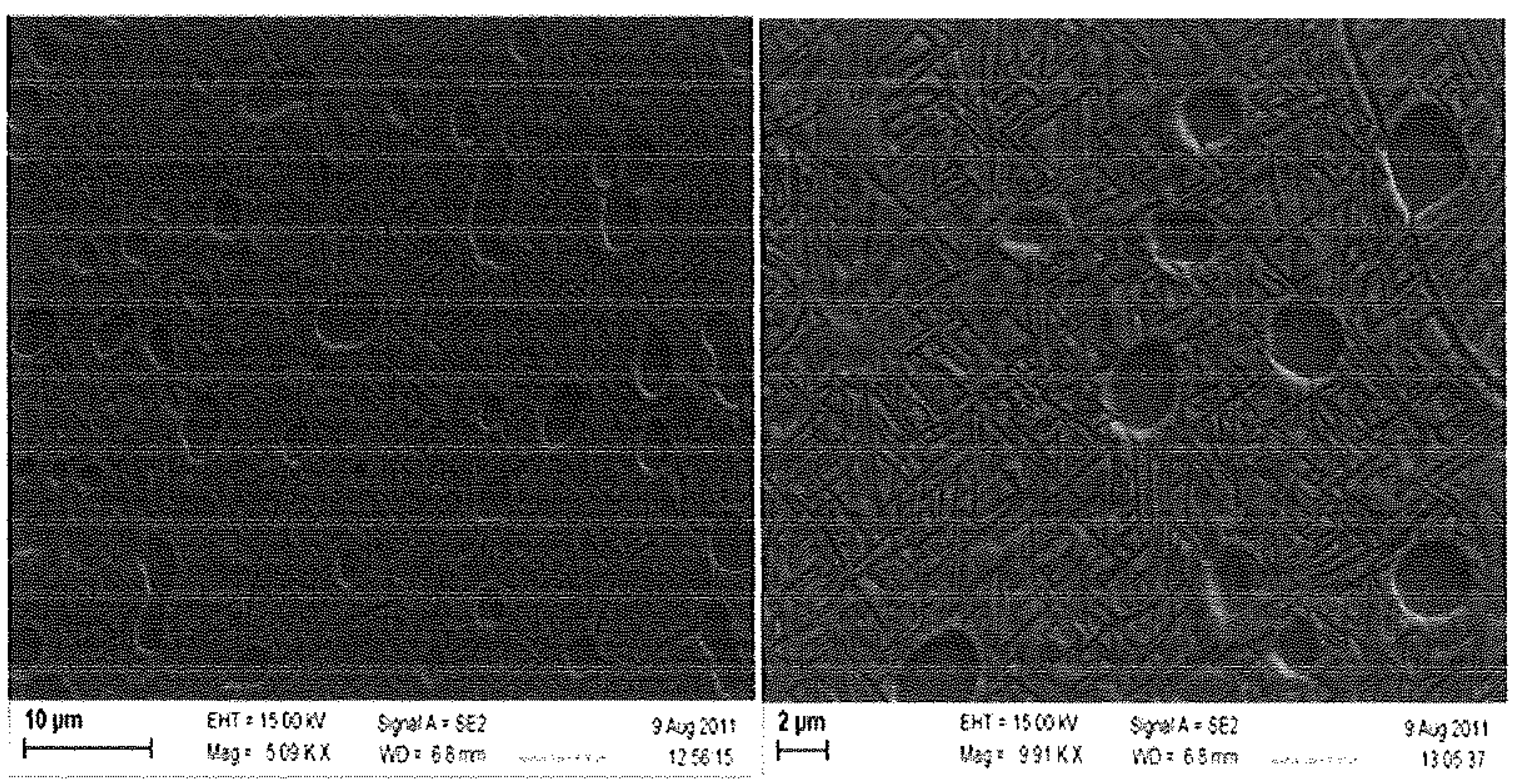

(b)

Fig. 3 Microstructures of the Ti5553 atloy. (a) Ti5553-1, (b) Ti5553-3.

average values calculated from 12 specimens (four strain rates and three specimens by strain rate) for each microstructure. Poisson's ratio was found to be equal to 0.35 for both microstructures (calculated from 2 tensile specimens for each microstructure). This ratio was measured by adding a radial extensometer to the axial extensometer used classically to measure the axial strain in the tensile direction.

\section{Viscoplastic behaviour}

Figure 4 (a) and (b) shows the eflect of the strain rate on the viscoplatic behaviour of both microstructures. The values shown in the small box in Fig. 4 (a) and (b) $(0.00005$; $0.0002 ; 0.004 ; 0.01)$ define the strain rates expressed in $\mathrm{s}^{-1}$ used to perform the tensile tests. In order to accurately analyze the effect of the strain rate on the stress-strain curve, a magnification of the stress domain (1000 $\mathrm{MPa}$, 


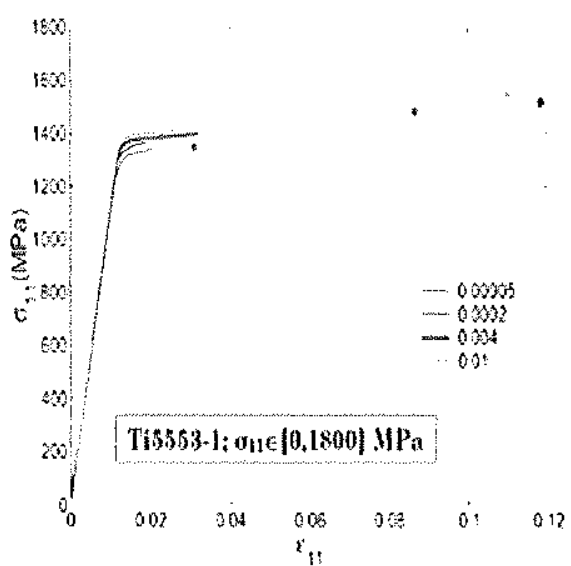

(it)

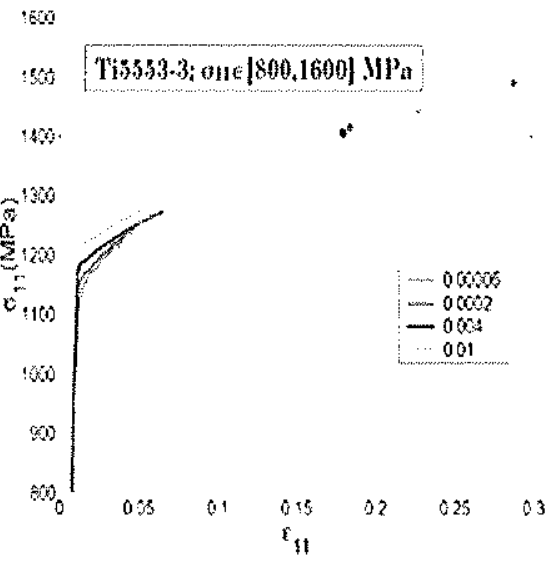

(c)

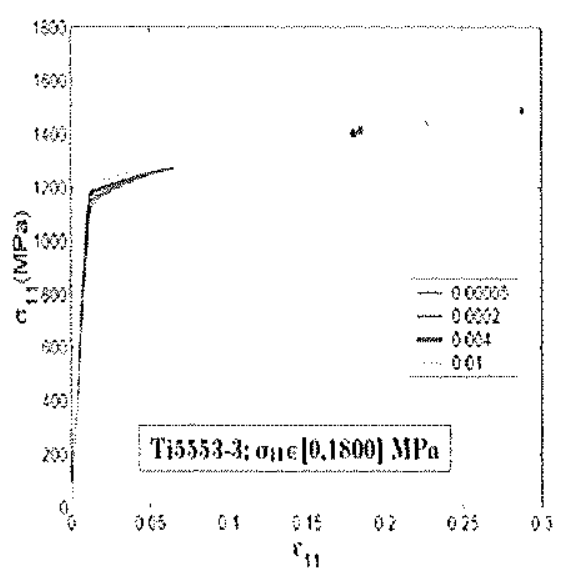

(b)

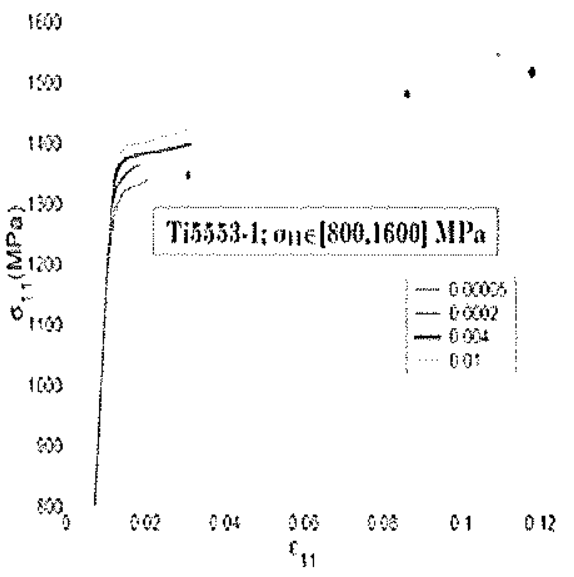

(d)

Fig. 4 Effett of the strain rate on the stress-strain curves.

$1600 \mathrm{MPa}$ ) is shown in Fig. 4 (c) and (d). Only the average curve over the three duplicate specimens is presented. It is clear, for both microstructures, that strength increases with the strain rate. In Ref. [2], it was demonstrated (on the basis of several mechanical tests such as shear, compression and plane strain tensile tests) that the plasticity for both microstructures can be assumed to be isotropic and follows the Von Mises yield function. Figure 5 shows that the strength of Ti5553-1 is higher than the strength of Ti5553-3. The viscoplastic properties can be correlated with the microstructure, which is a result of the heat treatment: a lower second aging temperature for microstructure Ti5553-1 results in a higher strength compared to Ti5553-3. Further explanations of these results are given in section 'Effect of the size of the secondary $\alpha$ precipitates'.

A mechanical constitutive relationship, frequently used for titanium alloys, ${ }^{12}$ is the Norton-Hoff model. This law was developed by Norton, ${ }^{22}$ and was generalized to three dimensions by Hoff, ${ }^{23}$ It defines the Von Mises equivalent stress or the yield stress $\bar{\sigma}$ in terms of the accumulated Von Mises equivalent strain $\bar{\varepsilon}$ and strain rate $\overrightarrow{\dot{\varepsilon}}$ (Eqn. (2)). The use of the Von Mises criterion is extensively justified in Ref. [2]. The material model of Equn. (2) refers to the general three dimensions stress state, but experimental tests are uniaxial tensile tests and only the strain component along the longitudinal direction is provided. In this case the strain component is equal to the equivalent strain untill the necking event. After that, the tests are no more uniaxial and the equivalent strain cannot be determined by a single extensometer. Data after the necking event cannot be considered to identify the material model parameters if no $\mathrm{FE}$ inverse modelling and digital image correlation are used to identify the multiaxial stress and strain field to this paper, the stress-strain curves are stopped when the uniaxial stress reaches a maximum. According to Considére criterion, necking has not yet happened at this moment. This model takes into account many physical phenomena: strain rate dependency, hardening, softening. The law fitted on the 


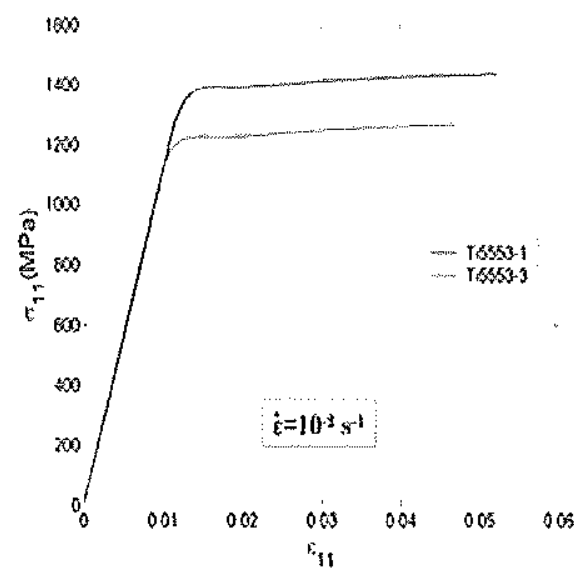

(a)

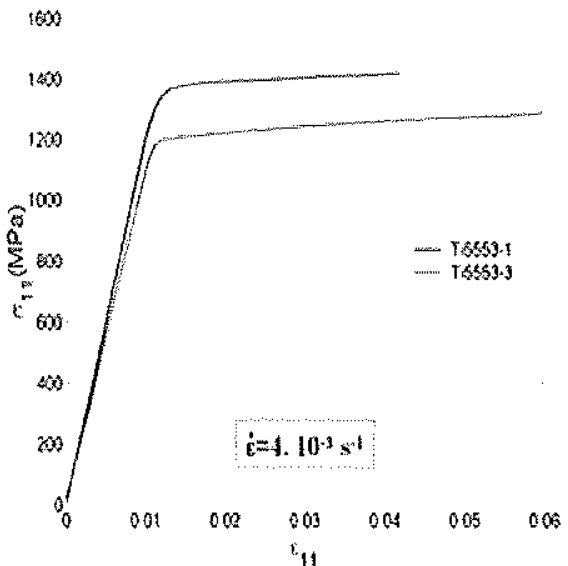

(b)

Fig. 5 Comparison between the seress-strain cotres of Ti5553-1 and Ti5553-3.

basis on the umiaxial tensile tests presented in Fig. 4 is:

$\bar{\sigma}=\exp \left(-P_{1} \bar{\varepsilon}\right) \sqrt{3} P_{2}(\sqrt{3} \overline{\dot{\varepsilon}})^{P_{3}} \bar{\varepsilon} p_{4}$

where:

$P_{1}$ : is the sottening parameter.

$P_{2}:$ is a scaling factor.

$P_{3}:$ is the strain rate sensitivity parameter.

$P_{f}:$ is the hardening parameter.

The material parameters $\left(P_{1}, P_{2}, P_{3}\right.$ and $\left.P_{4}\right)$ are adjusted to fit the Norton-Hoff law to the average of experimental curves. In this aim, a fitness scalar function (noted hereafter $R$ ) is defined to describe the 'distance' between the experimental results $\bar{\sigma}_{s}^{L x}(\bar{\varepsilon}, \bar{\varepsilon})$ (where s refers here to the number of the duplicate tensile tests ranging between 1 and 3 ) and the Norton-Hoff curve $\bar{\sigma}^{N \prime}(\overline{\dot{\varepsilon}}, \vec{\varepsilon})$ as evaluated with a given set of parameters values. The experimental curves and the Norton-Hoff curves are sampled at different strain positions ( 200 points) which are used to evaluate $R$ as follows:

$R(\bar{\sigma})=\sum_{S=1}^{j} \sum_{\overline{\dot{k}}} \sum_{\bar{\varepsilon}}\left(\bar{\sigma}_{s}^{k x p}(\overline{\dot{\varepsilon}}, \bar{\varepsilon})-\bar{\sigma}^{N H \prime}(\overline{\dot{\varepsilon}}, \bar{\varepsilon})\right)^{2}$.

The optimal set of material parameters $\left(P_{1}, P_{2}, P_{3}\right.$ and $\left.P_{4}\right)$ is obtained by a minimization of the fitness function $R$. This minimization was performed with a homemade python script involving the Nelder-Mead Simplex algorithm. For more details about this algorithm, see Ref. [24]. $A$ better description of the script used in this algorithm is given in the Appendix.

Equation (2) contains the elastic and plastic components of the strain. However, this law does not model the beginning of the curve. The elastic part is replaced by Hooke's law:

$\bar{\sigma}^{\prime l}=E \bar{\varepsilon}^{l}$
Table 2 Nortom-Huff paramezers of Ti5553-1 and Ti5553-3 tnicrostructures

\begin{tabular}{lllll}
\hline & $P_{1}$ & $P_{2}$ & $P_{3}$ & $P_{4}$ \\
\hline Ti5553-1 & 0.00187 & 982 & 0.006 & 0.045 \\
Ti5553-3 & 0.005 & 872 & 0.0035 & 0.05 \\
\hline
\end{tabular}

where $E$ is the Young's modulus (identified for both microstructures in section 'Elastic behaviour') and $\vec{\varepsilon}^{t}$ is the elastic strain in the tensile direction. The total model is composed of Hooke's law for elastic strain and of NortonHoff's law for viscoplastic strain. The later is used when the elastic linear curve intercepts that of Norton-Hoff. So for a given equivalent strain value, the corresponding equivalent stress is the minimum of the Norton-Hoff and Hooke's law as computed for that strain value.

These parameter values are provided in Table 2 (for the two microstructures).

It should be noted that the value of the parameter $P_{3}$ corresponding to the Ti5553-1 microstructure is larger than the value of the same parameter identified for the Ti5553-3 microstructure. This means that the Ti5553-1 microstructure is more sensitive to the strain rate than the Ti5553-3 microstructure. This can be easily observed from Fig. 4.

Table 3 summarizes the yield stress $\sigma_{\mathrm{p} 0.2}$ (experimentally measured at $0.2 \%$ of plastic strain) and the ultimate stress $\sigma_{1}$ for each of the strain rates. The ultimate stress value is provided by an average of the stress computed from the measured sample section at rupture for each specimen (as in section 'Geometry of the specimens'). These stresses are expressed in MPa.

The results presented in Table 4 are further illustrated in Fig. 6. 
Table 3 Effect of the strain rate on the experimental yield stress $\sigma_{1+3)}$

\begin{tabular}{|c|c|c|c|c|}
\hline \multirow[b]{2}{*}{$\dot{\varepsilon}\left(s^{-1}\right)$} & \multicolumn{2}{|c|}{ Ti5553-1 } & \multicolumn{2}{|c|}{ Tis $5553-3$} \\
\hline & $\left.\sigma p^{i}\right) .2$ & $\sigma_{u}$ & $\sigma_{1}, 2$ & $\sigma_{u}$ \\
\hline $5 \times 10^{-i}$ & 1285 & 1398 & 1142 & 1282 \\
\hline $2 \times 10^{-4}$ & 1313 & 1419 & 1150 & 1297 \\
\hline $4 \times 10^{-3}$ & 1332 & 1423 & 1185 & 1,300 \\
\hline $10^{-2}$ & 1370 & 1452 & $11 \%$ & 1318 \\
\hline
\end{tabular}

Table $\&$ The different values of $\sigma_{\text {min }}, \sigma_{\max }$ and $\sigma_{a}$ applied for the fatigne tests

\begin{tabular}{lrrrrrr}
\hline$\sigma_{\min }(\mathrm{MPa})$ & 40 & 66 & 75 & 86 & 93 & 110 \\
$\sigma_{\max }(\mathrm{MPa})$ & 400 & 660 & 755 & 866 & 933 & 1100 \\
$\sigma_{2}(\mathrm{MP})$ & $181)$ & 300 & 340 & 390 & 420 & 495 \\
\hline
\end{tabular}

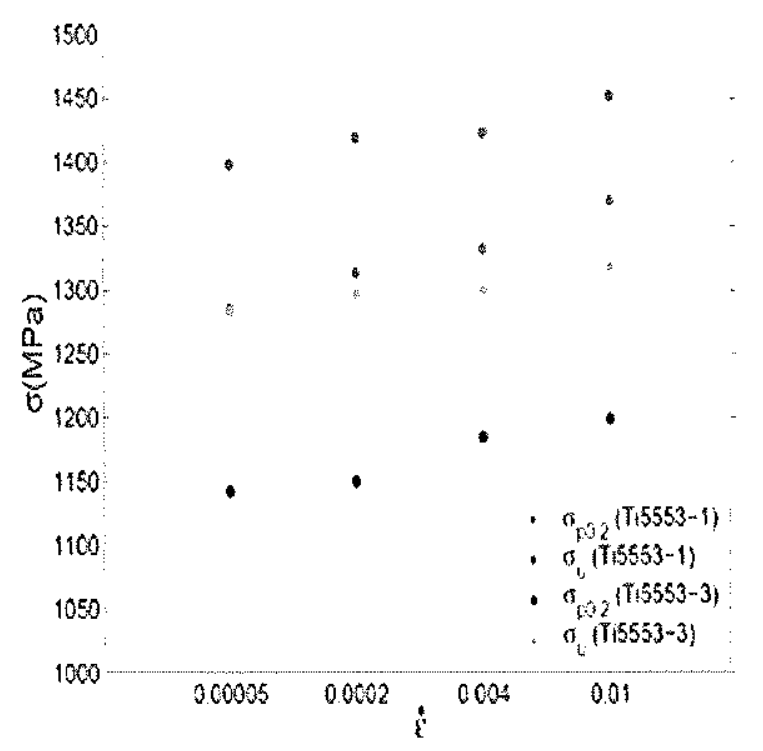

Fig. 6 Evolution of the experimental $\sigma_{p}$, and the experimental $\sigma_{\mathrm{a}}$ as a function of $\dot{\varepsilon}$.

For information, Lutjering and Willians reported in Ref. $\{11\}$ that the yield stress $\sigma_{\text {pi.2 }}$ of the Ti5553 alloy is between 1090 and $1100 \mathrm{MPa}$, respectively, for a $\beta$ annealed microstructure and for a bi-modal microstructure. It must be noted that the processed conditions (forging and heat treatment) used to elaborate the Ti5553 microstructures studied in Ref. [11] are not the same as the conditions used in order to elaborate the microstructures studied in the present work. This can explain the difference in the value of the yield stress between the different microstructures.
Analysis of the effect of the strain rate and the mictostructure on the elastoviscoplastic behaviour

The aim of the present subsection is to analyze and interpret the effect of the strain rate and the microstructure (especially the size of the $\alpha$ secondary precipitates) on the mechanical behaviour (initial yield stress, ultimate stress).

\section{Effect of the strain rate}

Classically strain rate increase generates higher stress level in most materials, "S 'This effect is confirmed for the two studied microstructures on the initial yield stress $\sigma_{[0.2}$ and ultimated stress $\sigma_{\mathrm{u}}$. These stresses increase moderately with strain rate, which is consistent with the bibliographic results (see for example Refs $[29,30]$ ). This strain rate effect can be explained by the theory proposed by Johnson and Gilman." Johnson and Gilman relate the imposed strain rate $\dot{\varepsilon}$ to the velocity of the mobile dislocations $v$ as:

$\dot{\varepsilon}=\rho b v$,

where $\rho$ is the dislocation density and $b$ is the burgers vector. The dislocation velocity is in turn related to the shear stress $\tau$ by the relation $\left.v=\left(\tau / \tau_{1}\right)\right)^{m^{\prime}}$, where $\tau_{i}$ and $m^{\prime}$ are material constants. Thus a higher imposed strain rate would entail a higher velocity for dislocation motion and hence a higher stress for triggering of plastic deformation at the macroscopic level.

\section{Effect of the size of the secondary $\alpha$ pretipitates}

The effect of the size of the secondary $\alpha$ precipitates on the strength (initial yield stress $\sigma_{1,2}$ and the ultimated stress $\sigma_{u}$ ) can be explained by the Hall-Petch effect. ${ }^{25.26}$ This relation assumes that the yield stress is inversely proportional to the square root of the grain size. Physically this effect assumes that the gram boundaries beween the $\beta$ phase and the secondary $\alpha$ precipitates act as barriers to dislocation motion. As the size of secondary $\alpha$ precipitates is smaller and their number is higher in the microstructure Ti5553-1 than in the Ti5553-3 microstructure, there are more a barriers in the first microstructure than in the second one. So the stress required to move the dislocations is higher for Ti5553-1 microstructure.

\section{DAMAGE PROPERTIES OF THE TI5553 MICROSTRUCTURES}

\section{Geometry of the specimens}

It is common to study the damage of materials on the basis of experimental tensile tests on notched axisymmetric specimens. In this study, tests were performed on 

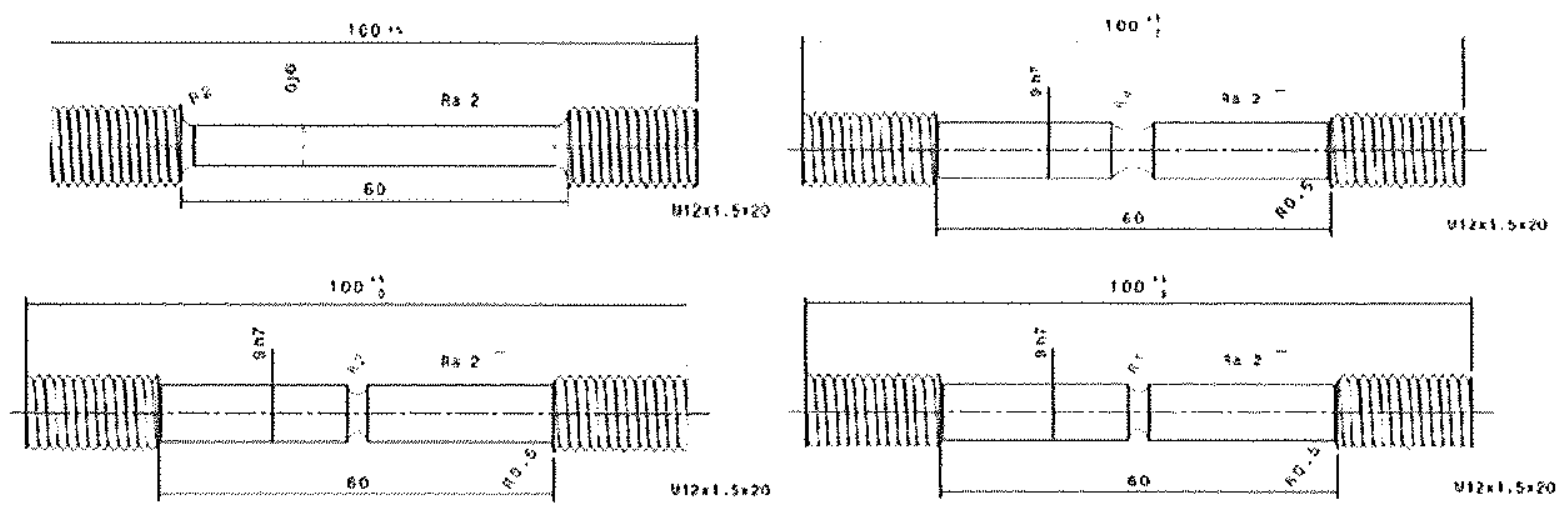

Fig. 7 Geometry of the smooth and notched tensile specimens.

samples with three different notch root initial radii $R_{0}$ equal to 1,2 and $4 \mathrm{~mm}$. The initial diameter in the gauge section was kept constant at $6 \mathrm{~mm}$ for all specimens tested. The geometry of the notched specimens is provided in fig. 7. The different notches induce different levels of hydrostatic tension (which induce different triaxiality levels) in the specimens during straining, which distinctly affect both the true stress and the strain to falure of the material. Three duplicate tests were conducted for each case (each temperature, notch radius, alloy and microstructure). During the tests, the applied load, the crosshead displacement and the diameter reduction (at the minimum cross-section) were continuously measured.

The ductility of the material, defined by the true fracture strain $\varepsilon_{f}$ is computed by the following relation:

$\varepsilon_{f}=\operatorname{Ln}\left(A_{0} / A_{f}\right)$

where $A_{i}$ and $A_{f}$ are the initial and final sections of the specimen. The initial section $A_{0}$ was exactly measured prior to testing.

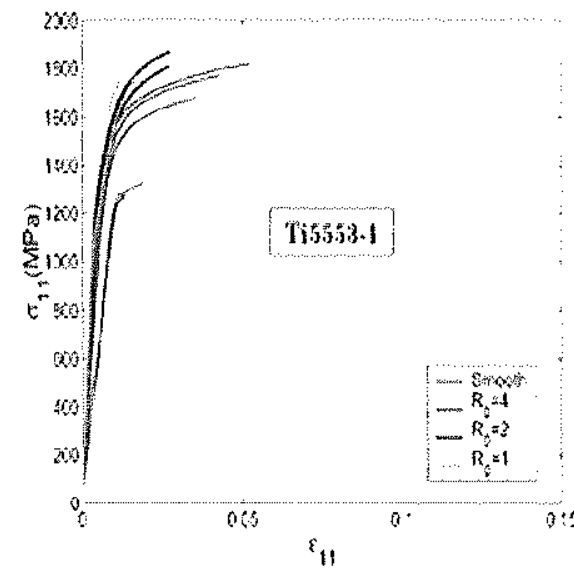

Fig. 8 Effect of the initial notch radius on the stress-strain curves.
Experimentally, the minimum cross-section after fracture $A_{f}$ is determined by using optical microscopic measurement available in MMS laboratory of ULg.

\section{Experimental results}

\section{Effect of the notd radius on the axial stres-strain curve}

The effect of the notch radius on the experimental axial stress component versus the tensile strain, for smooth and notched round specimens is given in Fig. 8 (three curves for each radius corresponding to the three duplicated tests). The stress is calculated by dividing the experimental force by the area of the current minimm notch cross-section. The curves are interrupted at the maximum stress. The main trend that the stress increases with decreasing initial notch radius is also well captured in FE simulations. Note that the apparent elastic modulus (the slope of the stress-strain curve) increases also with triaxiality.

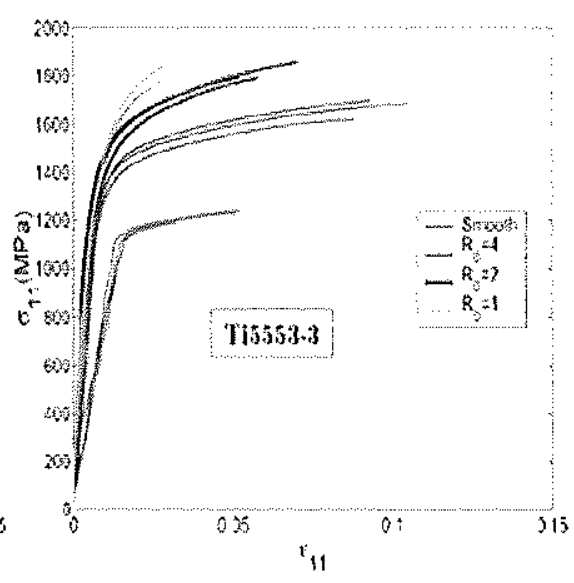




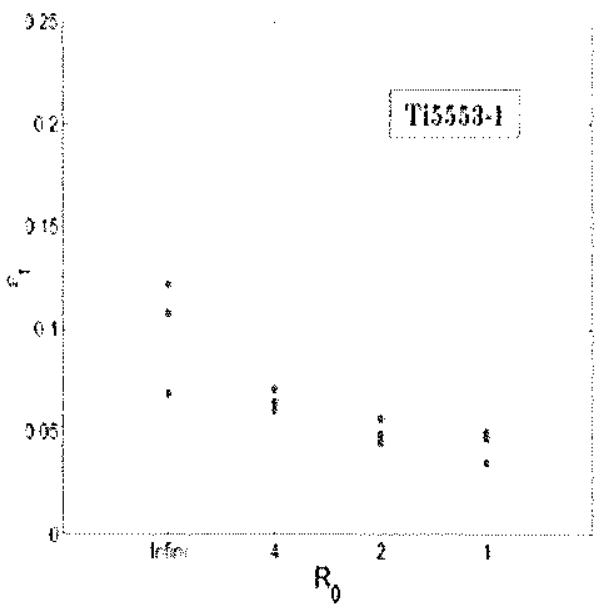

Fig. 9 Effect of the initial notch radius on the fracture strain.

\section{Effect of the initial notbl radius on the fracture strain}

The fracture strain, experimentally determined according to Eqn. (6), is plotted as a function of the initial notch radius (over the minimum necking section). As expected, it is apparent from the results of Fig. 9 that the ductility of the tested microstructures is strongly dependent on the value of the initial notch radius. The triaxiality in the minimum section is inversely proportional to the notch radius. It is demonstrated in many scientific works and theories ${ }^{27.28}$ that ductility at failure and triaxiality are nonlinearly in. versely proportional: the more stress state is triaxial, the less the strain at failure is. So the fracture strain is nonlinearly proportional to the notch radius. This result is experimentally observed. Indeed, it is seen that the specimen with $4 \mathrm{~mm}$ initial notch radius has globally harger strain to fracture than the specimens with initial notch radius equal to 1 and $2 \mathrm{~mm}$, respectively. 'The expected general tendency for fracture strain to increase with increasing notch profile radius is clear but there is a lot of scattering in the results. This large dispersion in fracture strain is also observed for other titanim alloys, like the Ti-6Al-4V alloy (see Ref. [3]). This dispersion may be due to a non-controlled difference in the microstructure elaboration or heat treatment (inducing for example a non-controlled heterogeneity of the grain size...). Unfortunately, we are not able at this level to give a definitive confirmation to the explanation of this phenomenon. Further investigation is required in order to better understand this dispersion.

The grain boundary of the secondary $\alpha$ precipitates is derrimental to tensile ductility of the Ti5553 alloy. Indeed high suress concentration and local suain occur at this grain boundary, especially at triple points. In these regions, crack initiates and propagates along grain boundaries and fracture occurs even at low macroscopic strains. As the numerical density of the secondary alpha precipi-

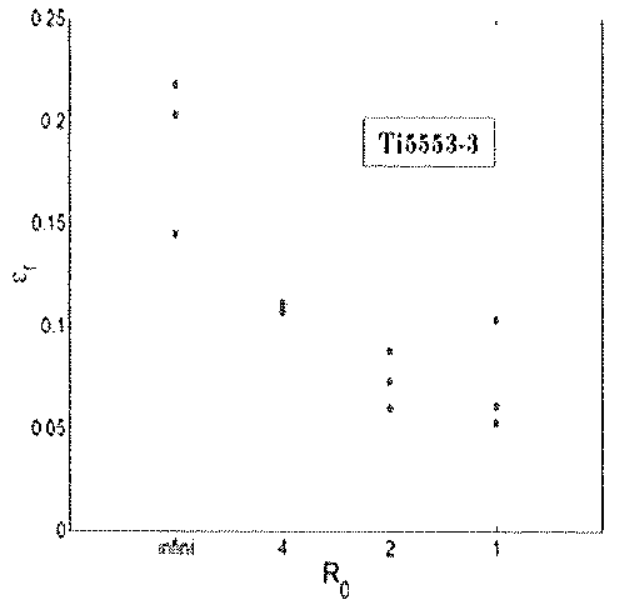

tates is statistically higher (in the case of the Ti5553-1 microstucture compared to the Ti5553-3 microstructure, the fracture occur earlier in the first microstructure.

\section{FATIGUE EXPERIMENTS AND RESULTS}

\section{Geometry of the specimens}

The geometry of the fatigue specimens is presented in Fig. 10. Cylindric specimens were extracted from the pancakes (one pancake from each microstucture) by the MSM laboratory at ULg, using the electric discharge machining technique (Fig. 11). The specimens were finally

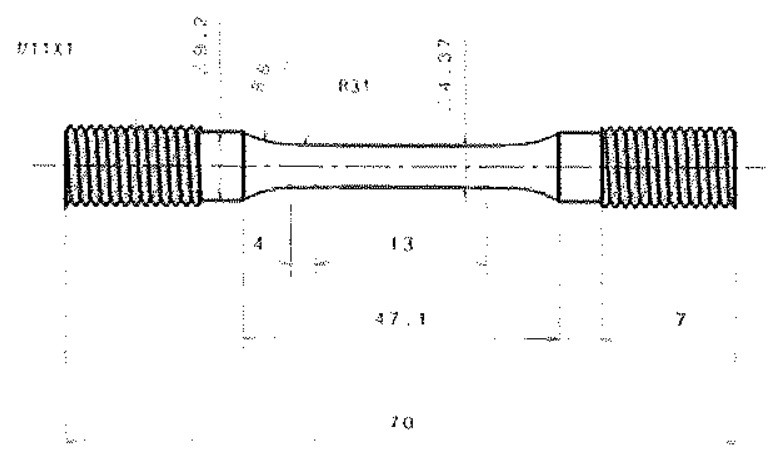

Fig. 10 Geometry of the Ti5553 fatigue specimens.

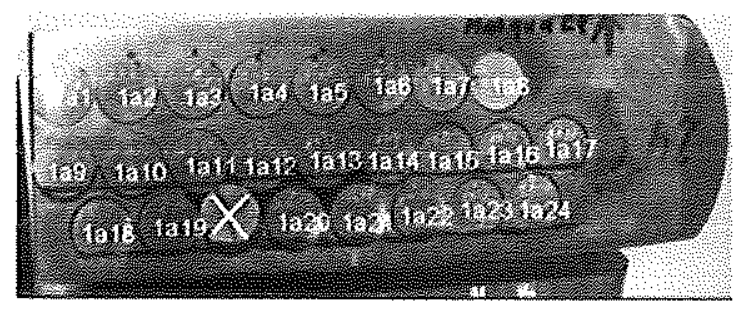

Fig. 11 Extraction of the specimens from the initial pancakes. 
machined by the Metcut Research Inc (Cincinnati, Ohio, USA) to meet the machining standards of Techspace Aero. Forty-nine specimens were machined: 24 specimens of the Ti5553-1 microstructure and 25 specimens of 17i5553-3. Forty specimens were tested at the ULg laboratory (20 specimens for each microstructure) and 9 at Metcut Research Inc (a haboratory qualified to carry out fatigue tests) in order to compare the results between them.

\section{HCF tests}

High cycle fatigue (HCF) tests were conducted, in accordance with the ASTM E466-02 standard, at room temperature and with a stress ratio $R\left(\sigma_{\text {inin }} / \sigma_{\text {max }}\right)$ of 0.1 , where $\sigma_{\min }$ and $\sigma_{\max }$ are, respectively, the minimm and the maximum stress during the loading cycle. The different values of $\sigma_{\min }, \sigma_{\max }$ and the magnitude stress $\sigma_{\mathrm{a}}=$ $\left(\sigma_{\max }-\sigma_{\min }\right) / 2$ are given in Table $4 . A$ sinusoidal loading was applied at a frequency of 125 and $80 \mathrm{~Hz}$ at UT.g and Meteut, respectively. The analyzed domain ranged from $10^{4}$ to $2 \times 10^{7}$ cycles. If a sample reached $2 \times 10^{7}$ cycles without failure, the test was stopped and the sample was considered unbroken ('run out' on the Wöhler curves).

\section{EXPERIMENTAL RESULTS OF THE FATIGUE TESTS OF THE TI5553 MICROSTRUCTURES}

\section{Wöhler curves}

High-cyclic fatigue tests are the most widely used technique to establish the fatigue limit of a chosen metal by essentially generating the $S-N$, or the Wöler, curve [the evolution of the alternated stress $\sigma_{a}$ with the number of cycles to failure (NR)]. The identified $S-N$ curves of the two investigated microstructures are presented in Fig. 12. Only the results corresponding to the ULg tests are presented here. Curves were built by the Techspace Aero company using a simple Bastenaire model, ${ }^{32}$ For each stress level, a minimum of three specimens were tested.

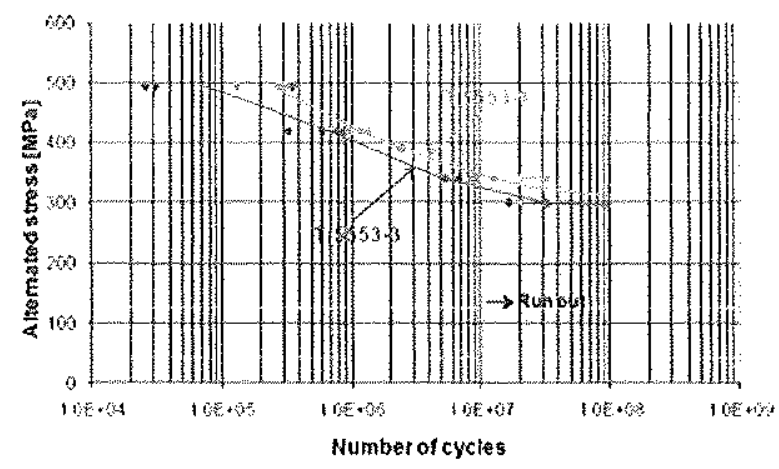

Fig. $12 \mathrm{~S}-\mathrm{N}$ corves (Wöhler) of the Ti5553 microstructures.
Table 5 Comelation between the static propertics and the fatigate properties of the Ti5553 alloy

\begin{tabular}{lcc}
\hline & $T i 5553-1$ & Ti5553-3 \\
\hline$\sigma_{\text {pul at } \dot{\varepsilon}=4 \times 10^{-3} \mathrm{~s}^{-1}}$ & 1332 & 1185 \\
$\sigma_{\mathrm{u}} \mathrm{at} \dot{\mathrm{s}}=4 \times 10^{-3} \mathrm{~s}^{-1}$ & 1423 & 1300 \\
Fatigue limit at $2 \times 10^{7}$ & 330 & 310 \\
Fatigue limit $/ \sigma_{p_{0}} 0.2$ & 0.261 & 0.275 \\
Fatigue limit $/ \sigma_{u}$ & 0.244 & 0.251 \\
\hline
\end{tabular}

As indicated in Fig. 12, Ti5553-1 exhibits a slightly higher endurance linit than Ti5553-3. It should be noted that the experimental results obtained at ULg were similar to the results obtained at Metcut Research Inc. 'The 'run out' of the Ti5553-1 and the Ti5553-3 occurred at 340 and $300 \mathrm{MPa}$, respectively. The endurance limit defined at $2 \times 10^{7}$ was equal to 348 and $326 \mathrm{MPa}$ for the Ti5553-1 and Ti5553-3 microstructures, respectively.

The comparison of the fatigue properties of the two microstructures may be correlated with a similar trend noticed for the tensile strength of the two microstructures in Table 5. From this table, it is clear that an increase in tensile strength led to an increase in fatigue strength, It is interesting to note that a decrease in the size of the secondary $\alpha$ precipitates have a positive effect on the yield and tensile strength ( $\mathrm{H}$ all-Petch effect as mentioned in section 'Effect of the size of the secondary $\alpha$ precipitates') while generally improving fatigue strength by retarding the crack initiation. The enhanced resistance to crack initiation is considered as a result of high strength of fine grains that act as potential obstacles for dislocation movement, and thereby the formation of microcracks is inactive. ${ }^{16.33-37}$

In conclusion, the latigne behaviour of the two microstructures of the Ti5553 alloy is linked to changes in the microstructures that occur as a result of small modifcations in heat treatment. After analysis, it seems that no clear relationship between the fatigue limit and the initial position of the extracted specimen in the pancake can be observed.

\section{Fractographic analysis}

The fatigue fracture surfaces were observed with a scanning electron microscope in order to understand the fracture mode. From this examination (see Fig. 13), it is clear that the majority of the specimens (from the two microstructures) present a crack initiation on $\alpha$ nodules depleted in chromium and molybdenum. From the same examination, fatigue crack initiation generally seems to occur at grain boundaries or at a triple point. No significant clear difference is found between the fracture mechanisms of the two microstructures. 'These conchisions are 

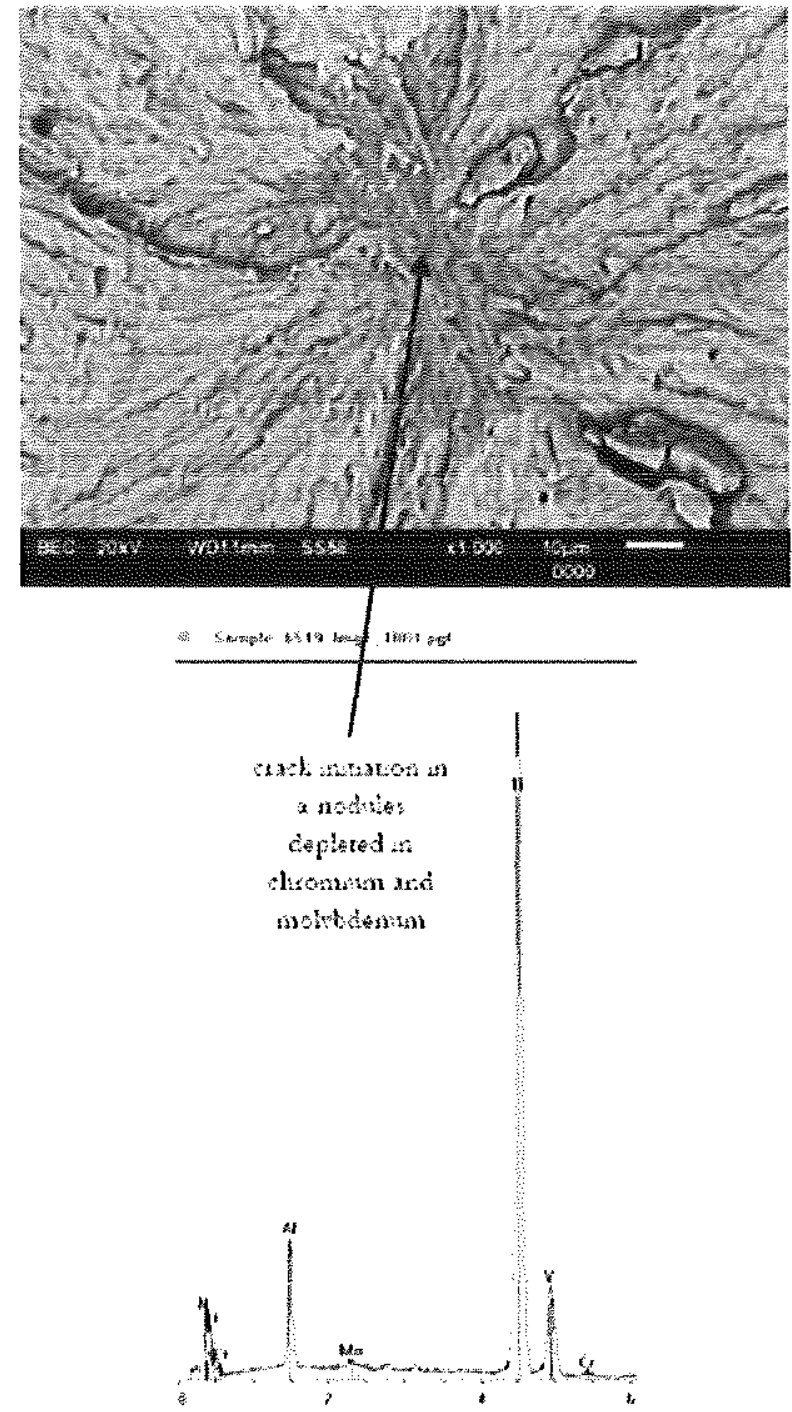

(a)

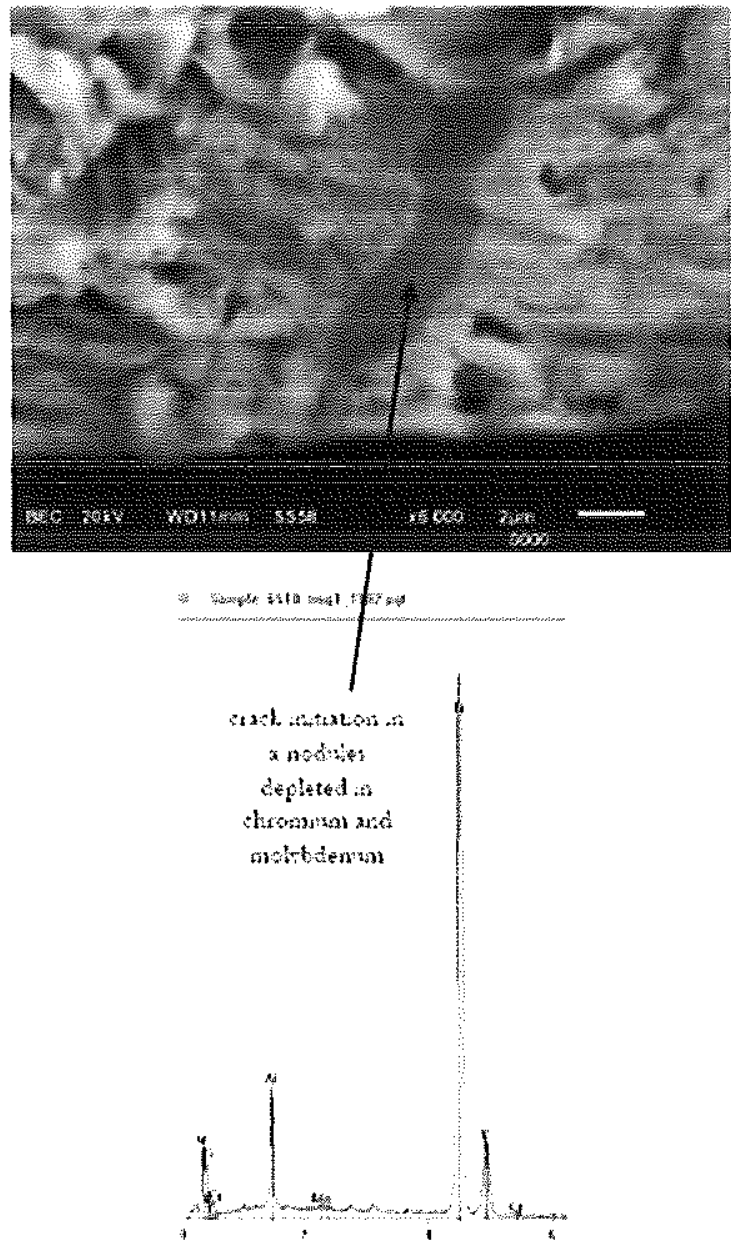

(b)

Fig. 13 Fracture surfaces of Ti5553-1 specimens.

drawn from analysis of 10 specimens from the Ti5553-1 microstructure and 8 specimens from the Ti5553-3 microstuncture.

\section{COMPARISON OF FATIGUE RESULTS \\ OF THE TWO STUDIED TI5553 ALLOY MICROSTRUCTURES WITH THOSE OF TWO OTHER TITANIUM ALLOYS, TIAO AND Ti-6Al-4V}

\section{Fatigue properties of Ti40 and Ti-6Al-4V}

- Ti40 is a commercially pure low-iron grade 2 titanium con taining $0.03 \%$ iron or less. ${ }^{38}$ The alloy is double vacum melted by the consumable electrode arc melting process.

Russo and Schöbe ${ }^{3 y}$ studied Ti 40 ingots forged and rolled into a 44.4 or $50.8 \mathrm{~mm}$ thick plate product. The plate product was annealed at $730 \mathrm{C}$ for $30 \mathrm{~min}$ and air cooled. The frequency of the fatigue tests corresponding to the Ti40 was set to $20 \mathrm{~Hz}$. The stress ratio $R$ was equal to 0.1 and the fatigue tests were performed at room temperature. The yield stress (resp. the ultimate stress) of this alloy in the heat treatment conditions cited previously is about 960 MPa (resp. $985 \mathrm{MPa}$ ) as mentioned in Ref. (40).

- Bellows et al. ${ }^{+1}$ studied Ti-6Al-4V, an alloy forged into fan blade forging tools, measuring approximately $400 \times 150$ $\times 20 \mathrm{~mm}$, in a single forging campaign by the Cleveland Operations of Textron Turbine Engine Components. The forging stock had been double vacuum are remelted, converted to $64 \mathrm{~mm}$ diameter bar stock, and supplied in the 


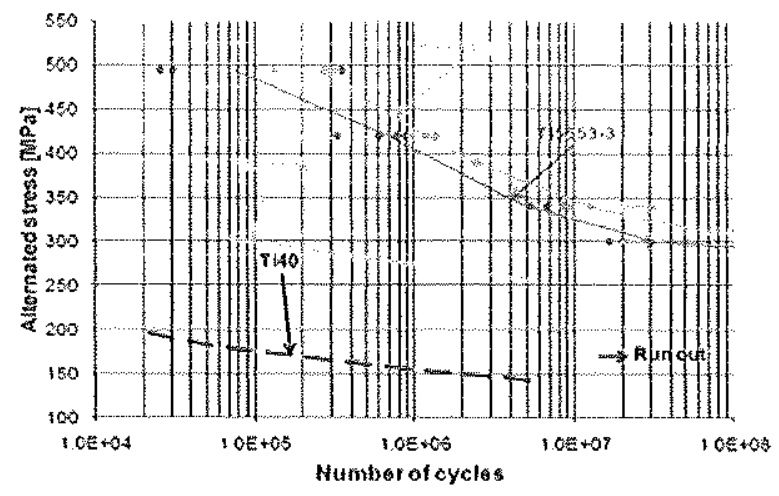

Fig. $14 \mathrm{~S}-\mathrm{N}$ curves of Ti5553, TA6V and Ti40 alloys $(R=0.1)$.

mill-annealed condition in accordance with AMS4928L. ${ }^{42}$ The frequency of the fatigue tests corresponding to the 'Ti-6Al-4V was set to $60 \mathrm{~Hz}$. The stress ratio $R$ was equal to 0.1 and the fatigue rests were performed at room temperature. The yield stress (resp. the ultimate stress) of this alloy is about $1100 \mathrm{MPa}$ (resp. $1170 \mathrm{MPa}$ ).

It is clear that the yield stress and the ultimate stress of the titanium alloys depend on their chemical composition, heat treatment and the applied strain rate. But it can be concluded, despite the dispersion, that the strength (yield stress and ultimate stress) of the Ti5553 alloy (both microstuctures) is superior to the strength of the $\mathrm{Ti}-6 \mathrm{Al}-4 \mathrm{~V}$ alloy which is superior to the strength of the Ti40 alloy.

\section{S-N curves}

A comparison of the fatigue test results obtained in this research study with the $S-N$ curves of the above alloys Ti40 and 1 $1-6 \mathrm{Al}-4 \mathrm{~V}$ is shown in Fig. 14. It demonstrates that the high-cycle tatigue resistance of both $1 \mathrm{~T} 5553 \mathrm{mi}$ crostructures is noticeably better than the high-cycle htigue resistance of the Ti40 and Ti-6Al-4V alloys. This result can be explained by the difference of the yield stress and the ultimate stress between the different alloys. Indecd an increase in the yield stress and the ultimate stress is accompanied by an increase in the fatigue strength.

The fatigue strength of Ti5553 (fatigue limit cqual to $429 \mathrm{MPa}$ at $10^{6}$ cycles and $404 \mathrm{MPa}$ at $10^{6}$ cycles for the Ti5553-1 and Ti5553-3 microstructures, respectively) is largely superior to the limit fatigue (at $10^{6}$ cycles) of the Ti40 alloy (equal to $155 \mathrm{MPa}$ ) and of the Ti-6Al-4V (equal to $274 \mathrm{MPa}$ ).

\section{Goodman diagrams}

Several models are traditionally been used for constant life diagrams; the first and probably the most popular is

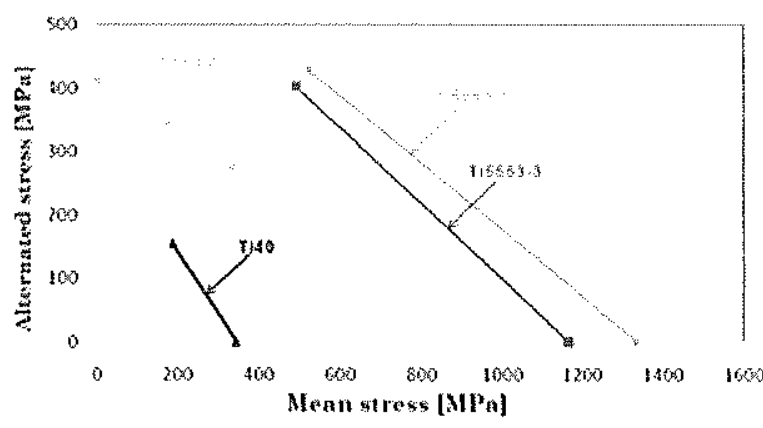

Fig. IS Goodman diagrams of Ti5553, TAGV and Tito alloys.

the Goodman diagram. ${ }^{43.44}$ In this case, the magnitude stress $\sigma_{a}$ is plotted as a function of the mean stress $\sigma_{m}$ in the following way:

$\sigma_{\mathrm{a}}=\sigma_{\mathrm{a}}\left(\sigma_{\mathrm{m}}=0\right) *\left(1-\frac{\sigma_{\mathrm{n}}}{\sigma_{\mathrm{u}}}\right)$

where $\sigma_{a}=\sigma_{a}\left(\sigma_{11}=0\right)$ is the limit fatigue for completely reversed loading and $\sigma_{\mathrm{u}}$ is the ultimate tensile stress.

In Fig. 15, the Goodman diagram corresponding to the different alloys and microstructures studied in Fig. 14 is constructed at $10^{6}$ cycles and at room temperature with available data. So, in the case of Ti5553-1, Ti5553-3 and Ti40, a straight line is drawn connecting the point $\left(\sigma_{\mathrm{m}}\right.$, $\sigma_{3}$ ) determined from Fig. 14 at $10^{6}$ cycles to the ultimate tensile strength on the mean axis. In the case of Ti-6AI$4 \mathrm{~V}$, a straight hine is drawn connecting the point $\left(\sigma_{\mathrm{m}}, \sigma_{3}\right)$ determined at $10^{6}$ cycles from Fig. 14 (so at $R=0.1$ ) with the point $\left(\sigma_{m}, \sigma_{3}\right)$ determined at $10^{6}$ cycles from Rei. [4I] at a stress ratio of $R=-1$ (the Ti-6Al-4V specimens used for the two stress ratios 0.1 and -1 came from the same supplicr).

Figure 15 undoubtedly confirms the superiority of the fatigue properties of the Ti5553 alloys in comparison with the other alloys.

\section{CONCLUSIONS}

This paper presents and discusses the experimental results of a recent experimental study aimed to determine the static (elastoviscoplastic and (lamage) and high-cycle fatigue behaviour of two distinguish microstructures of the new Ti5553 titanim alloy. The difference between the two microstructures is related to the value of the temperature of the second aging which induces a difference of the size of the secondary $\alpha$ phase. It is interesting to note that a decrease in the size of the secondary $\alpha$ precipitates have a positive effect on the yield and tensile strength (Hall-Petch effect as mentioned in section 'Effect of the size of the secondary $\alpha$ precipitates') and a negative effect of the ductility while generally improving fatigue 
strength by delaying the crack initiation. The enhanced resistance to crack initiation is considered as a result of high strength of fine grains that act as potential obstacles for dislocation movement, and thereby the formation of microcracks is less inactive. A fractographic analysis is carried out in order to understand the fatigue mechanisms in both microstructures (Ti5553-1 and Ti5553-3). This analysis reveals that fatigue crack initiation generally seems to occur at gram boundaries or at a triple points and no significant clear difference was found between the fracture mechanisms of the two microstructures. The static and fatigue properties of Ti 5553 were also compared with the fatigue properties of two other titanium alloys, Ti40 and $\mathrm{T} i-6 \mathrm{Al}-4 \mathrm{~V}$. The results of various studies have shown that the '1 15553 alloy exhibits substantially superior static and fatigue characteristics relative to other titanium alloys and in particular in comparison with the Ti-6Al-4V alloy, which is the most popular titanium alloy. This comparison confirms the well-known idea stating that an increase of the yield stress and the ultimate stress is accompanied by an increase in the fatigue strength. This nukes Ti5553 a promising material tor advanced aeronautical applications.

\section{Acknowledgements}

The authors thank the Walloon Region (Winnomet Titaero Project), the Belgian Scientific Research Fund FNRS, which finances A.M.H., and the Interuniversity Attraction Poles Program, Belgian Science Policy P7, for their financial support.

\section{REFERENCES}

1 Srivatsan, T. S., Soboyejo, W. O. and Leterich, R. J. (1905) The cyclic fatigue and fracture behavior of a titanium alloy' metal matrix composite, Lng. Frat. Mccb. 52, $467-491$.

2 Ben Betuieb, M., Van Honf, T., Dufour, P', Lenain, A., facupues, P.-I. and Habraken, A.-B. Comparison beween the mechanical behavior of Ti6Al4V and TiS553 alloys. I'art I: dasticity, viscoplasticity and plastic arisotropy. Mater. Sit. Eng. $A$ (submitted).

3 Ben Bettaieb, M., Van Hoof, T., Minnebo, H., Dufour, P., Lenain, A. and I Labraken, A.-M. Comparison between the nechanical behavior of Ti6Al4V and Ti5553 alloys. Part II: damage characterization and numerical validations. Matrr. Sit. Eng. A (submitted).

4 Clement, N. (2010) Phase transformations and mechanical properties of the $\mathrm{Ti}-5553 \mathrm{~h}$-metastable titanim alloy, $\mathrm{PhD}$ Thesis, UCL, Belgium.

5 Li, S. J., Cui, T. C., Hao, Y. L. and Yang, R. (2008) Fatigne propertics of a metastable beta-type titanimm alloy with reversible phase transformation. Aita Biomater: 4, $305-317$.

6 Lin, C.. -IV, Ju, C..-P. asul Chern l.in, J.-H. (2005) $\Lambda$ comparison of the fatigut behavior of cast T; $-7.5 \mathrm{Mo}$ with c.p. titaniam, $\mathrm{Ti}-6 \mathrm{Al}-4 \mathrm{~V}$ and $\mathrm{Ti}-13 \mathrm{Nb}-13 \mathrm{Zr}$ alloys. Biomaterials 26, $2899-209 \%$.

7 Gedaty, A. F. (2009) Mechanical behavior of Ti-5553 alloy: moleling of representative cells, $\mathrm{PhD}$ Thesis, Ulg, Belgium.

8 Boyer, R. R, and Briggs, R. D. (2005) The use of $\beta$ titanium alloys in the aerospace industry. 7. Noter. Fins. Paform. 14, $681-685$.

9 Arrazoli, P.J., Garay, A., Iriarte, L.-M., Armendia, M., Matya, S. and Le Mâtre, $\mathrm{F}$ (2009) Machinability of titanium alloys (Ti6AlaV and Ti555.3).7. Hater. Proicis. Tibnol. 209, $2223-2230$.

10) Casavola, C., pappalettere, C. and Tatoli, F. (2009) Experimental and numerical study of static and fatigue properties of titaniam alloy welded joints. Mroh. Mater. 4I, $231-243$.

11 Litjering, G. and Williasns, ]. C. (2007) Titamitm. 3nd eth. Springer-Vertag, Berlin.

12 Sarrazin-Baudeux, C. (2005) Abnormal near-threshold batigue crack propagation of $\mathrm{Ti}$ alloys: role of the microstructurc, $\mathrm{Int}$. 7. Fatigut 27, 773-782.

13 Berteaux, O., Jutiad, M., Thonas, M. and Hénaff, (x. (2006) Microstructure-low cycle fatigue behaviour relationships in a PM r-TiAl alloy, Intometallio 14, 1130-1135.

If Kumpfert, J., Kimb, Y. W. and Dimidak, D. M. (1095) Effect of microstructare on fatigute and tensile properties of the gamma TiAl alloy Ti-46.5A1-3.ONh-2,1C.r-6.2 V V. Mater. Sci Eng. A 192/193, 465-473.

Is Marny, P., Leguey, T., Belianow, I. and Victoria, M. (2000) Tensile and fatigue properties of two titanium alloys as candidate materials for fusion reactors. 7. Nul. Watcr. 283-287, 602-606.

16 Nakajima, K., Terao, K. and Miyata, T. (1998) The effect of micrestructure on fatigate crack propagation of $\alpha+\beta$ ticanizun alloys in-situ obsertation of short fatigue crack growth. Mater. Sit. Eng. $1243,176 \mathrm{~m} 181$.

17 Srivatsana, T.S., Bathinib, U., Panaikb, A. and Quick, $\Gamma$, (2010) A study of cyclic fatigue, damage initiaton, damage propagation, and fracture of welded titanium alloy plate. Wate' Sci. Eng. A $\$ 27,6644-6659$.

18 Fujita, T., Ishikawa, M., Hashimoto, S., Minakawa, K. and Ouchi, C. (1993) Beta Titanium Alloys in the 1900's. In: Procedings of the Symposim, TMS Anmual Meting, Denver, CO, USA, Pl. 297-307.

19 Polmear, I. J. (1095) Light Alloys, Anold, lonton.

20 Kubiak, K, and Sicniawski, J. (1998) Development of the microstructure and fatigue strength of two phase titanium alleys in the processes of forging and heat treatment. 7 . Matcr. Process. Teibnol. 78, 117-121.

21 Willet, Y. (2007) Fantille des alliages de titane. Bomnes pratiugues \& incerdits, foumes Tedonologiques TTANL, Nantes, France.

22 Norton, F. H. (1929) Crecp of Sted at Higb Temperalure. He Grow-Hill, New-York.

23 Hoff, N.1. (1954) Approximate analysis of stmucture in the presence of moderately large creep deformation. Q. Appl. Wati. 12, 49-55.

24 Nelder, J. and Mest, R. (1965) A simplex method for function minimization. Comput. $7.7,308-313$.

25 Hall, E. O. (1951) The deformation and ageing of mild sted: III discussion of results. Proc. Pbys. Sic. Sec. B., 64, 747-753.

26 Pech, N.J. (1953) The clcavage strength of polycrystals. 7. Iron Sted Inst. 174, 25-28. 
27 Rice, I. R. and Tracey, D. M. (1969) On the ductile enlargement of voids in triaxial stress fields. 7. Meib. Pbys Solits. 17, 201-217.

2S Hancock, I. W. and Meckenzie, A.C. (1976) On the mechanisims of ductile faiture in high strength steels subjected to multi-axial stress-states. 7. Mcob. Pbys. Solits. 24 $147-16 \%$

20 Semiatin, S. L. and Bieler, T. R. (2001) The effect of alpha platedet thickness on plastic flow during hot working of '1i-6Al-4V with a transfonmed microstructure. Adta Water: 49 , $356,5-3573$.

30 Venkatesh, B. D., Chen, D. L. ;nd Bhole, S. D. (2009) Effect of heat reatment on mechanical properties of Ti-6. Al-4V ELI alloy. Hat Sit Eng at-Stut $506,117-124$.

3) Johnston, W. G. and Gilman, J. 1. (1959) Disletation velocities, dislocation densities, and plastic flow in lithium flucride crystals. 7. Appl. $\mathrm{Pby}$. 30, 129-144.

32 Bastenate, F. A. (1972) New mether for be statistical evaluation of constant stress amplitude fatigne-test results. Probabilistic aspects of fatigue. ASTM STP 511, 3-28.

33 Tokiaj, K., Ogawa, T. and Ohya, K. (190) The effect of grain size on small fatigue crack growth in pure titanium. Troms. 7 SWE $58,178-185$

34 'Turner, N. G. and Roberts, W. T. (1968) Fatigne behavior of tianium. AWWE Trans. 242, 1223-1230.

35 Lucas, J. J. and Konieczny, P. P. (1971) Relationship hetween Apha grain size and crack initiation fatigute strength in Ti-6Al-4V. Metall. Mater. Thams. B. 2, 911-912.

36 Stubbington, C. A. and Bowen, A. W. (1973) The effect of section size on the fatigue properties of $\mathrm{Ti}-6 \mathrm{Al}-4 \mathrm{~V}$ bars. In Procedings of the Serond International Conference. Cambridge, Mass, USA, pp. 1283-1296.

37 Wagner, L. and Lutjering, (., (1987) Nicrostruckurat infuence on propagation hehavior of short cracks in an (alpha+ beta) titanitu alloy. Z. Metal/kd. 78, 369-375.

38 Boyer, R, Coflings, E. W and Welsch, G. (1094) Haterials Properties Handbonk: Titaniun Alloys. ASM International, Ohio, USA

39 Russo, P. A. and Schöbel, J. D. (1982) Mechanical properties of commercially pure tiratum containing low iron. presentation at ACIEMA82, Franckfurt, West Germany.

40 Xin, S. W., Zhao, Y. Q. and Zeng, W. D. (2007) Effect of heat treatment on thermal stability of Ti40 alloy. Trans. Nonforous Mot. Soc. Clina 17, 526-531

41 Bellows, R. S., Muju, S. and Nicholas, 'T. (1992) Valitation of the step test method for generating Haigh diagrams for 1\%-6Al-4V. Int.7. Fitigue 21,687-697.

42 Aerospace materials speciffetion 'titanimm alloy bars, wire, forgings and rings, 6Nl-4V, annealed'. Warrendale (PA): SAZ International, Society of Automotive Engineers. 19\%).

43 Goodman, J. (1991) Mechanics Applied to Engineering. Longmans Green, London, 1899 (as referenced in S. Suresh (1901) fatigute of Materials. Cambritge University Press, Cambridge).

4t Sendectyi, C. P. (1098) History of emstam life diagrams. In High Gyle Fatigu' of Sintumal Materials (Edited by T.S. Srivatsan and WY. O. Sobojcjo), TNS, Warcudale, PA, USA, pp. $95-107$

\section{APPENDIX: DETAILED DESCRIPTION OF THE NELDER-MEAD ALGORITHM}

\section{Nelder-Mead method}

A simplex method for finding a local minimum of a function of several variables has been designed by Nelder and Mead.

For two variables, a simplex is a triangle, and the method is a pattern search that compares function values at the three vertices of a triangle. The worst vertex, where $f(x, y)$ is largest, is rejected and replaced with a new vertex. A new triangle is formed and the search is contimued. The process generates a sequence of triangles (which might have different shapes), for which the function values at the vertices get smaller and smaller. The size of the triangles is reduced and the coordinates of the minimum point are found

The Nelder and Mead's algorithm is stated using the term simplex (a generalized triangle in $N$ dimensions) and will find the minimum of a finction of $N$ variables. It is effective and computationally compact.

\section{Initial triangle $B G W$}

Let $f(x, y)$ be the function that is to be minimized. To start, we are given three vertices of a triangle: $V k=(x k$, $y k), k=1,2,3$. The function $f(x, y)$ is then evaluated at each of the three points: $z k=f(x k, y k)$ for $k=1,2,3$. The subscripts are then reordered so that $z 1 \leq z 2 \leq z 3$. We use the notation

$B=\left(x^{1}, y^{1}\right), G=\left(x^{2}, y^{2}\right), \quad$ and $W=\left(x^{3}, y^{3}\right)$

to help remember that $B$ is the best vertex, $G$ is good (next to best), and $W$ is the worst vertex.

\section{Midpoint of the goud side}

The construction process uses the midpoint of the line segment joining $B$ and $G$. It is found by averaging the coordinates:

$M=\frac{B+G}{2}=\left(\frac{x_{1}+x_{2}}{2}, \frac{y_{1}+y_{2}}{2}\right)$.

\section{Reflection using the point $R$}

The function decreases as we move along the side of the triangle from $W$ to $B$, and it decreases as we move along the side from $W$ to $G$. Hence it is feasible that $f(x, y)$ takes on smaller values at points that lic away from $W$ on the opposite side of the line between $B$ and $G$. We choose a test point $R$ that is obtained by 'reflecting' the triangle through the side $B G$. To determine $R$, we first find the 
midpoint $M$ of the side $B G$. Then draw the line segment from $W$ to $M$ and call its length $d$. This last segment is extended a distance $d$ through $M$ to locate the point $R$. The vector formula for $R$ is

$R=M+(M-W)=2 M-W$.

Expansion using the point $E$

If the function value at $R$ is smaller than the function value at $W$, then we have moved in the correct direction towards the minimum. Perhaps the minimum is just a bit farther than the point $R$. So we extend the line segment through $M$ and $R$ to the point $E$. This forms an expanded triangle $B G E$. The point $E$ is found by moving an additional distance $d$ along the line joining $M$ and $R$. If the function value at $E$ is less than the function value at $R$, then we have found a better vertex than $R$. The vector formula for $E$ is:

$E=R+(R-M)=2 R-M$.

\section{Contration asing the point $C$}

If the function values at $R$ and $W$ are the same, another point must be tested. Perhaps the function is smaller at $M$, but we camnot replace $W$ with $M$ because we must have a triangle. Consider the two midpoints $C 1$ and $C 2$ of the line segments $W M$ and $M R$, respectively. The point with the smaller function value is called $C$, and the new triangle is $B G C$.

Note: The choice between $C 1$ and $C 2$ might seem inappropriate for the two-dimensional case, but it is important in higher dimensions.

\section{Sbrink touards B}

If the function value at $C$ is not less than the value at $W$, the points $G$ and $W$ must be shrunk towards $B$. The point $G$ is replaced with $M$, and $W$ is replaced with $S$, which is the midpoint of the line segrnent joining $B$ with $W$.

\section{Logical decisions for each step}

A computationally efficient algorithm should perform function evaluations only if needed. In each step, a new vertex is found, which replaces $W$. As soon as it is found, further investigation is not needed, and the iteration step is completed. The logical details for two-dimensional cases are explained in the following table.

\begin{tabular}{|c|c|}
\hline \multicolumn{2}{|c|}{ IF $f(R)<f(G)$, THEN Perform Case (i) \{either reflect or extend\} } \\
\hline EEGN \{Case (i), $\}$ & BEGN \{Case (ii). $\}$ \\
\hline $\begin{array}{l}\text { F } f(B)<f(R) \text { THEN } \\
\text { replace } w \text { with } R\end{array}$ & $\begin{array}{l}\text { IF } f(R)<f(W) \text { THFN } \\
\text { replace } W \text { with } R\end{array}$ \\
\hline ELSE & $\begin{array}{l}\text { Compute } C=(W+M) / 2 \\
\text { or } C=((W+M) / 2 \text { and } f(C)\end{array}$ \\
\hline Compute $E$ and $f(E)$ & Wf $f(C)<f(W)$ THEN \\
\hline $\begin{array}{l}\text { IF } f(E)<f(R) \text { THEN } \\
\text { replace } W \text { widh } E\end{array}$ & $\begin{array}{l}\text { replace } W \text { with } C \\
\text { ELSE }\end{array}$ \\
\hline $\begin{array}{l}\text { ELSE } \\
\text { rephace } W \text { with } R\end{array}$ & $\begin{array}{l}\text { Compute } S \text { and } f(S) \\
\text { replace } W^{7} \text { with } S\end{array}$ \\
\hline ENDIF & replace $G$ with $M$ \\
\hline NDIF & ENDIF \\
\hline ND $\{$ Case (i). $\}$ & END $\{$ Case (ii). $\}$ \\
\hline
\end{tabular}


